\title{
Digital Platform Antitrust Approaches
}

\author{
Mokronosov A.* Anisimova M.
}

\author{
Ural State University of Economics, Yekaterinburg 620144, Russia \\ *Corresponding author.Email: Amokronosov@mail.ru
}

\begin{abstract}
This research focuses on approaches to competition regulation of digital platforms, which are presented as systems with market structure and transaction network. The characteristic features of digital platforms are marked, the main instruments of obtaining and holding market power, forms of abuse of dominant position in the relevant market are marked. On the basis of a synthesis of scientific research and existing practice in handling antitrust cases, the principal provisions for regulating digital platforms are shown. It is noted that the division of digital platforms into transactional and nontransactional allows to determine the number of relevant markets that are affected by the actions of the platform. A number of platform digital properties have been identified that are important for assessing the boundaries of relevant markets. Special attention is paid to identifying the dominant position of the digital platform based on the analysis of a number of related conditions: consolidation of large data, the impact of network effects; economies of scale. The role of analysis focused on future potential competition in digital markets for the development of innovations is highlighted.
\end{abstract}

Keywords: competition, antitrust regulation, digital platforms

\section{INTRODUCTION}

The development of the digital economy has led to the proliferation of platforms that use data-driven business models and transform existing industries. In a broad sense, digital platforms are multilateral markets of both their own services and other services related to the platform, and in a narrower one, they simplify the interaction of manufacturers and consumers.

Characteristic of digital platforms are continuous innovation, constant changes and improvements in their functionality to meet the rapidly growing consumer demand. It is the innovative process that gives the digital platform market power. As the main tool for obtaining and maintaining market domination, the market domination platform is user information, which can be used to restrict competition and drive competitors out of the market. Network effects of a digital platform, manifested by drawing consumers into the supply chain, consolidating their loyalty, form the market power of the platform. The dominance of the digital platform arises simultaneously in a multitude of markets that it controls, allowing it to have a multiplier effect. [1].

The digital platform does not change only the business but also the format of competition, carries the risks of widening inequalities in access to knowledge and technology, establishes control over consumer groups as well as ownership of user information. The new digital realities present a challenge for regulating competition. The increasing variety of risks in the digital sphere predetermines the formation of new requirements for the development of approaches and tools for antitrust regulation of the digital economy, including platforms. Many papers have been published recently on the development of digital market regulation strategies. This study presented attempts to systematize research in this area and to offer an understanding of approaches and tools for the antimonopoly regulation of digital platforms.

\section{RESEARCH METHODOLOGY}

The problem of adapting antimonopoly regulation to the needs of the digital economy was not ignored by economic science. The analysis of studies on the character of antitrust regulation as applied to digital markets made it possible to determine the properties of its instruments and their target focus. According to T. Maxwini, antitrust should be flexible to apply to digital markets [2]. A. Ezraci rightly considers the key feature of regulation to be its dynamism, allowing to solve a wide range of economic and social issues [3]. J. Amato suggested that antitrust laws form the stability of the digital market system being built [4].

In the Russian scientific literature, the issues of research of digital markets and their regulation are presented in the reseach of E. Vojniknikanis, A. Ivanova, A. Tsarikovski, who note the need for a balanced approach to regulation by restraining the dominant force of technological titans without compromising innovative development [5]. Approaches to understanding the content of competitive strategies of multilateral digital platforms, researched by A.I. Kovalenko, can be useful in forming a model for regulating the competitive environment of the digital economy. It is proposed to use the concept of "forming strategy", which allows to reveal in detail the competitive 
actions of multilateral platforms regarding the environment and business eco-system [6]. In the work of A.E. Shastitko, E.N. Parshina systematized a list of criteria for determining bilateral digital platforms in order to apply antitrust laws; It has shown that a too broad interpretation of bilateral digital platforms can become a regulatory problem [7]. However, issues related to determining the dominance of digital platforms, the boundaries of relevant markets, need to be clarified. The research has been prepared on the basis of general scientific methods of knowledge applied in economic science, adapted to the nature of digital technology markets. The study uses evolutionary and institutional approaches. The use of the evolutionary approach is conditioned by the specifics of regulation of competitive relations in digital markets. The institutional approach is based on an assessment of competition threats associated with the increased market power of digital monopolies. The application of these research methods is aimed at the validity of the results of the analysis.

\section{RESEARCH RESULTS}

A summary of scientific research and existing practice in handling antitrust cases in the Russian Federation and EU countries has shown that regulation of digital platforms is based on the following principles:

1. Transition to a flexible antitrust system regulation, providing the possibility of choice and implementation of a digital platform of business strategy in order to adapt to increasing competition [8].

2. Providing deterrence dominant the power of digital platforms without compromising innovative development.

3. The focus of regulation is not only on real, but also potential competition of digital platforms in order to identify positive and negative effects for consumers and society as a whole.

4. A comprehensive review of factors that impact competitive conditions on the digital market, including an assessment of the features of the development of new

technology, the role of big data, network effects as tools to gain competitive advantage.

5. The formation of the legal field id not taking into account only understanding the need for maximum use of the potential of the data economy by digital platforms, but also the creation of antitrust measures when big data can violate competition in the digital market.

These regulatory provisions stem from the characteristics of digital platforms markets and are based on the need to ensure conditions to stimulate competition by creating innovative value for the consumer and society.

With the beginning of the digitalization of the economy, a number of specialists expected that most of the "traditional" antitrust regulations would not be needed, and that a complete modernization of the legislation would be required. However, competition authorities have managed to solve a number of problems associated with adapting traditional tools to the features of digital platforms [9]. An example of this is the approach to the analysis of the dominant digital platforms in the case of Google, which applied by the Federal Antimonopoly Service of Russia and based on the peculiarities of goods consumption on the markets of application stores for mobile devices running the Android operating system, computer equipment and Internet commerce, as well as consumer reactions to these features [10].

Discussions on proper approaches and instruments of antimonopoly regulation of digital platforms are conducted both in academic studies and by practitioners. On the way to solving this problem, specialists have to face various problems. Thus, in the search on the economics of platforms there is still no unambiguous definition of them [11]. It makes more difficult to precisely define the boundaries of the multilateral market, since some consumer groups may receive services from the digital platform free of charge by paying attention to it [12]. In our opinion, it is a good idea to classify multilateral platforms into transactional and nontransactional in order to establish the number of markets that are used by the digital platform as an infrastructure for interaction between economic agents. Nontransaction markets are presented as sides of the digital platform that do not interact with each other. It requires competition authorities to identify relevant markets for each side of the platform. In case of direct interaction of the digital platform participants it is suggested to consider the transaction market as a single market [11]. Researchers in the digital economy have identified a number of features of platforms that are important for assessing the boundaries of markets that can be grouped together: the existence of a cross-networking effect; the importance of the level of not only the price set by the platform for economic exchange, but also the fee that is set for each of the independent user groups of the platform; the interaction of user groups in carrying out the transaction; the degree of integration, which determines the possibility of considering the platform as an intraindustry platform; and the level of integration [7, 14, 15, $16,17]$.

Thus, the digital platform is presented as a system with a market structure and a network of transactions, the essence of which should be defined in accordance with the set of the above criteria. It will allow the competition authority to correctly determine the number of relevant markets for the digital platform, their product and geographical boundaries. In addition, the most important parameter in assessing market boundaries in the digital economy is the time factor [5]. The dynamism of digital markets caused by the development of new, breakthrough technologies leads to a change in their configuration, which should be evaluated by competition authorities. The problems related to the definition of geographic and product borders of digital platforms markets have not yet been unambiguously solved and consolidated in methodological tools in our country. It seems that the Order of analysis of competition in the commodity market, approved by Order of FAS of Russia on April 28, 2010 № 220, should be supplemented by the relevant sections relating to digital markets, including platforms. 
Recent scientific literature has actively discussed approaches to determining the dominance of digital platforms as a key category in competition law, as well as the necessary analytical tools for calculation and justification. At the same time, a group of specialists voiced the position that antimonopoly regulation of digital monopolies - platforms can damage innovations, as they drive scientific progress. Antitrust authorities are encouraged to take a balanced approach to digital market pricing, focusing on the absorption of potential competitors (startups) and limiting access to the infrastructure of the digital world. [18]. This approach is certainly important, as unjustified state interference in the digital markets slows down the innovation process. The practice of dealing with competition cases shows that platforms undoubtedly abuse their dominant position and can limit competition, so the digital market flaws should be corrected through extensive direct government intervention in market processes.

The most important indicator of a business entity's dominant position in the market is its market share. In the case of digital markets, the calculation of this indicator may be difficult due to the lack of statistical information. The indicators currently used to estimate the market share of digital platforms are, in particular, the number of users and accounts. It might be advisable to supplement the existing methodological tools for calculating market share with alternative indicators that take into account the specifics of digital markets.

Establishing a dominant position for a digital platform based on market share alone is considered insufficient and requires an analysis of a number of concomitant conditions that limit competition in a relevant market: consolidation of large data in the hands of digital companies; mergers and acquisitions of digital platforms with large data; the impact of network effects; economies of scale. Specialists suggest fixing a special list of qualitative criteria of dominating position in the digital market in methodological documents. We believe that this proposal is appropriate provided that the list is not exhaustive, as the dynamism of the digital world and the high speed of change may cause the emergence of new types of barriers limiting competition in digital markets.

Given the high rate of change in digital markets, the problem of understanding the trends in the digital world is becoming a major one for both companies and competition authorities. The evaluation of the external market environment, the ability of digital companies to adapt to changes, and the smoothing of negative effects are of primary importance.

\section{RESEARCH RESULTS DISCUSSION}

The development of digital platforms has a significant impact on the changes currently taking place in economic systems at different levels. This study systematizes research in the field of adaptation of antimonopoly legislation to the requirements of the digital economy, in particular, digital platforms. In the future, there is a need for detailed studies to assess the impact of the dominance of digital platforms in relevant markets, as well as for a more detailed research of the features of digital platforms in order to clarify the methodological tools for antitrust regulation of such social and technological phenomenon.

\section{CONCLUSIONS}

The study showed that antitrust regulation of digital platforms remains a subject of discussion among scientists and practitioners. The complexity of regulating platforms is due to the dynamism and innovativeness of the digital economy markets. When considering antimonopoly cases in relation to platforms, it is important to form an approach that takes into account not only the specifics of new technologies, but also ensures the maximization of innovative opportunities and legal certainty for digital business in terms of the possibility of using certain business models. Setting up antitrust regulation tools for digital platforms that limit market power of digital platforms should include the following:

1. Definition of geographical and food the boundaries of the markets that are involved in the digital platform, based on an assessment of its features, including the presence of a cross-network effect; interaction of user groups during the transaction; the degree of integration that determines the possibility of considering the platform as an intraindustry or inter-industry intermediary; the degree of openness of the platform for new members; used business models.

2. Addition to the current methodological tools for calculating the market share of subjects with alternative indicators, which take into account the specifics of digital markets, in particular, the number of users, accounts.

3. Establishing a dominant position digital platform, taking into account the accompanying conditions that affect the restriction of competition in a relevant market: consolidation of big data, the impact of network effects, economies of scale.

4. Conducting an analysis focused on assessing the external market environment, the ability of digital companies to adapt to changes, smoothing out negative effects. These approaches will improve the effectiveness of regulatory actions in the digital sphere. 
Journal of Modern Competition, 2016, vol. 10, no. 5 (59), pp. 89-141.

[11] Beneke, F Ohio v. American Express and the Balancing of Consumer Welfare Effects on Multiple Sides of a Platform, International Review of Intellectual Property and Competition Law, 2019, 50 (7), pp. 917927. DOI: https://doi.org/10.1007/s40319-019-00861-6.

[2] McSweeny T.A. U.S. Enforcers Perspective: Protecting Competition and Promoting Innovation. Keynote Remarks of Commissioner. Taiwan International Conference on Competition Polic, Taiwan, 2016. URL: // https://www. fts/gov/ files/documents/ public_stratements/973233/mcsweeny_-_tftc_ keynote_6-29-16.pdf.

[3] Ezrachi A. Sponge, Journal of Antitrust Enforcement, Volume 5, Issue 1, April 2017, pp. 4975. DOI: https:// doi.org/10.1093/jaenfo/jnw011.

[4] Amato G. Antitrust and the bounds of power: the dilemma of liberal democracy in the history of the market, Oxford: Hart, 1997, Retrieved from Cadmus, European University Institute Research Repository, at: http://hdl.handle.net/1814/28819.

[5] Antimonopoly regulation in the digital age: how to protect competition in the context of globalization and the fourth industrial revolution, NAC. Research, University Higher school of Economics, FAS, 2018, $311 \mathrm{p}$.

[6] Kovalenko A. Shaping Strategy and Competitive Dispositions with Multisided Platform, Journal of Modern Competition, 2017, vol. 11, no. 3 (63), pp. 89117.

[7] Shastitko A., Parshina E. Two-sided markets: the subject matter specification. Journal of Modern Competition, 2016, vol. 10, no. 1, pp. 5-18.

[8] Competition policy in the prevention of restrictive business practices and anti-competitive state assistance, experience and practice of the European Union / A. Karaganchu, I.V. Knyazev; Ministry of Education and Science of the Russian Federation, Novosibirsk State University, Novosibirsk State Technical University. Novosibirsk, 2017, 232 p.

[9] Laitenberger J. The antitrust journey, Journal of Antitrust Enforcement, Volume 7, Issue 3, October 2019, pp. 314-318. DOI: https://doi.org/10.1093/jaenfo/jnz028.

[10] Vartaev R., Garaev R., Kovalenko A. Digital platforms dominance abuse (in Google case in Russia),
[12] Evans D. Basic principles for the design of antitrust analysis for multisided platforms, Journal of Antitrust Enforcement, Volume 7, Issue 3, October 2019, pp. 319-338. DOI: https:// doi.org/10.1093/ jaenfo/ jnz012.

[13] Ducci F. Procedural implications of market definition in platform cases, Journal of Antitrust Enforcement, Volume 7, Issue 3, October 2019, pp. 419-446. DOI: https://doi.org/10.1093/jaenfo/jnz017/.

[14] Luchetta G. Google opera in un mercato a due versanti? Mercato Concorrenza Regole, Rivista quadrimestrale, No 1, 2013, pp. 83-118. DOI: https:// doi.org/10.1434/73451.

[15] Semyachkov, K. A. Transformation of Economic Relations in the Conditions of the Development of Digital Platforms, Zhurnal Economicheskoj Teorii [Russian Journal of Economic Theory], 16(3), 2019, pp. 593-597.

[16] Russo F., Stasi M.L. Defining the relevant market in the sharing economy, Internet Policy Review, 5(2), 2016, pp. $2-10$. DOI: https:// doi.org/10.14763/2016.2.418.

[17] Zvereva, A. A., Belyaeva, Zh. S. \& Sohag, K. Impact of the Economy Digitalization on Welfare in the Developed and Developing Countries. Ekonomika regiona [Economy of region], 15(4), 2019, pp.10501062 .

[18] Til P., Masters B. From zero to one. How to create a startup that will change the future. $\mathrm{M}$.: Alpina Publisher, 2019, 192 p. 